Introduction to Special Issue, Traps: Concrete Technologies and Theoretical Interfaces Forthcoming (2019) in Journal of Material Culture

\title{
The Anthropology of Traps: Concrete Technologies and Theoretical Interfaces
}

\author{
Alberto Corsín Jiménez and Chloe Nahum-Claudel
}

\begin{abstract}
Traps connect not only predator and prey, but mind and materiality, technology and landscape, and infrastructure and ecology. Through them bodies, knowledge practices, materials, and environments are assembled in transformative encounters which, because of their lethal agency, have emotive and moral force. In this Introduction we explore the conceptual bridges and disciplinary admixtures invited by ethnographic attention to traps. We review a history of attention to traps, which is in the main a history of neglect and epistemological bias. As humble hunting technologies traps have been secondary in status to the heroic chase, and the lifeways of trappers at the frontiers of empires have been neglected. Meanwhile traps have featured as archetypes and prototypes in evolutionist discourses focusing on technology, and human crafty intelligence in its invention and advancement. We trace these threads from the nineteenth century to contemporary anthropology and archaeology, and propose conceptual and practical lines for future analysis and research collaboration.
\end{abstract}

In 1852 the Railroad Company began construction work on a railway line to the iron mining region on the southern shore of Lake Superior, Michigan. Lewis Henry Morgan was one of the directors and shareholders of the company, and starting in 1855, 'and nearly every summer since', took the opportunity to explore the opening of the wilderness afforded by the new line. In particular, he was drawn to 'a beaver district, more remarkable, perhaps, than any other of equal extent to be found in any part of North America' (Morgan 1868, viii). He observed that beavers had permanently modified the landscape, felling trees, excavating canals, and building dams, lodges and burrows. Morgan collected copious materials on beaver construction, anatomy, habitat and cognition. The resultant book, published in 1868 as The American Beaver and His Works, offers a close-up portrait of the fur trade that illustrates the mixtures of phenomena onto which traps become a window.

Coming from an era when anthropology and zoology could be approached in tandem, Morgan's book strikes us as surprisingly contemporary, insofar as nature and culture, materiality and ecology, cognition and symbolism, are apprehended in mixtures that are now, once again, becoming possible. Morgan describes the entanglement of infrastructures, ecologies, and intelligences around Lake Superior, where beavers continuously worked upon their meadows, dams and lodges right beside iron mines and railroads (Morgan 1868, 83, 112). His central interest is in reading beaver's 'free intelligence' - cognition as we would now call it - from the animals' construction and landscaping activities. This chimes with contemporary commitments in fields as diverse as evolutionary cognition (De Waal 2017: 28) and the post-humanities (Haraway 2008) to exploring the extent to which the endeavours of our own and others' species are both akin and entangled. The book is also an intriguing read from political-economy and 
ethics perspectives given Morgan's bluntness about the brutality of the steel leg hold traps used to capture beavers, and the displacement of beaver livelihood by frontier capitalism, which he nonetheless spearheaded.

In this Special Issue we wish to recover the heterodox mixture that Morgan's iconoclastic text reveals by focusing, like he did, on the descriptive richness of traps. We embrace the trap as a prosthesis for conceptual bridging and disciplinary admixture. In the very first Issue of this Journal, published in 1996, Alfred Gell made a similar claim when he found in traps a portal that linked anthropology to the art world (Gell 1996). He argued that hunting traps were artefacts of human skill with a particularly forceful agency because they gave material form to hunters' knowledge of animal prey, and put this knowledge to work in autonomous, animate and deadly technologies. For him, traps were uniquely potent mixtures of the ingenious, the aesthetically satisfying, and the poetically dramatic. The influence of Gell's text has been far reaching, inaugurating new approaches to the study of material culture, the anthropology of art, agency and distributed cognition. We engage critically with Gell to make a case for the study of traps as gateways to a world of ethnographic and conceptual possibility, and as enablers of multiple crossings between anthropology, archaeology, cognitive science, ecology, art, and computer science.

\section{Traps/Entrapments}

The conceptual creativity of the trap lies in its duplex identity as a noun and a verb. A trap refers simultaneously to a specific material interface (a trap) and to an analytical description of mutuality (entrapment). We wish to suggest here that entrapments are good to think with because they help us to see how engagement, complicity or exchange (or their reversals via deception and domination), necessarily operate via material and ecological vectors. In this sense, traps are bridges between meaning and materiality, human and thing, predator and prey, technology and ecology, ontology and epistemology. Traps assemble bodies, knowledge practices, materials, and environments in transformative encounters and consequential infrastructures. Moreover, entrapments always have intellectual, emotive and moral force because of their potentially lethal agency.

The rest of the Introduction is divided in four parts. In the first part we review the status of traps in the ethnographic record. Traditionally, traps were documented as the auxiliary equipment of hunting and were inventoried as part of a society's material culture. As a result, detailed descriptions of trap use and careful diagrams of trap construction mostly come from an era concerned with salvage documentation and diffusionist or evolutionary schemas, or from studies of subsistence strategies. Mining some of this literature, we begin, then, with a consideration of traps as hunting technologies. We show that traps gain their significance, and receive their definition, in a value-laden contrast with encounter hunting. Traps are both hunting technologies and they are the antithesis of the hunt, because they bring technological mediation into the human-animal relationship. While we would like to maintain a restricted definition of the trap as a technology that stands in lieu of the hunter and works in his absence, by discussing what we call body-traps and landscape-traps, we chart a continuum of preyengagement strategies.

In the second section we briefly situate trapping in the context of disruptive histories of empire and frontier capitalism. The role that indigenous trappers have played in various 
extractive economies has often been neglected, relegating both the technology and its designers to the margins of the colonial project. There is much work to be done in recentring them.

Section three focuses on the mechanics of cunningness and deceit that have generally been ascribed to trap designs. We are intrigued by the epistemological vectors underwriting this view of traps as technologies of crafty disguise. We trace this epistemological thread back to nineteenth century evolutionist interests (in Morgan, for example, but also in Otis Mason and others), yet find novel articulations of it in Gell's famous theory of enchantment, and contemporary archaeology's search for the origins of modern cognition.

Our last section attempts to take stock of some of the richest ethnographic and historical works on traps, and uses them to exemplify our anthropological theory of entrapment. We invite a consideration of entrapment as an idiom for anthropological complexity: a sensibility with which to pay attention to the entanglement of material and ecological relations, to the arts and traps of mutuality and complicity, captivation and liberation, yet including an awareness of the lurking presences of the uncanny, the predatory and the unruly.

\section{Hunting Traps: Low Cunning or the Triumph of Human Wit?}

In this section, hunting, a theme that has been of ongoing interest to anthropologists and archaeologists, provides a first framework for thinking about traps. To state the obvious, traps are hunting technologies, they are one class of 'thing' (to be neutral on where they stand on the tool-technology continuum) used in a human food quest that, in every social-environmental assemblage, employs various and differentially valued and symbolised strategies. As such, traps gain their significance and status in relation to alternative strategies.

Traps are ambivalently valued: they have been considered the pinnacle of evolved intelligence and ingenuity, and the precursors of emancipatory technological leaps, or, alternatively, as lowly, inferior forms of hunting, in which a device gets in the way of a direct, and therefore heroic, relationship between hunter and prey. In what follows we explore this emotive opposition between the immediacy of encounter hunting (man pursues and spears beast) and the spatial and temporal distancing of entrapment (watching, planning, thinking, preparing, setting, waiting, checking). Often this features as a value-laden contrast between the exercise of the passions and of the wits. Based on the liminal place of fishing in the hunting literature, we then argue that predation techniques are best viewed on a continuum of mediation and we offer a new conceptual vocabulary for forms of mediation.

In the Kalahari, a decisive site for the 'man the hunter' paradigm and thus a part of the world where hunting has received sustained attention, the archetypal hunt is the chase, the relentless pursuit of four-legged game on the savanna until it is 'brought to bay' and killed with a spear (e.g. Schapera 1930, 133). Richard Lee insists that for the !Kung San, trapping is 'certain, reliable and well under the control of rational methods and technological processes', engendering no ritual (Lee 1979, 305-6). What is more, in the savanna snares bring in a small and steady supply of low-status food packages, unlike the risky but profitable chase of large game mammals (Wadley 2010, 180). Plato, who wrote that fishing and trapping were idle amusements because 'the slothful hunter's 
work is done for him' by traps and nets (see Cartmill 1996, 31-32), seems to agree with the !Kung. Extroverted running, striking and shooting were apparently manifestations of godly heroism in ancient Greece and in his Laws Plato condemned traps for fostering cunning and duplicity and thereby undermining civic virtues (Detienne and Vernant 1991 [1977], 34).

We find similar moral condemnation of trapping among imperial British hunters of the late nineteenth century. As they wielded firearms to stalk trophies in the outposts of Empire, traps, snares and poisons were depreciated as devices for devious and unmanly Chinese hunters, and as antithetical to the British man's sport (Peckham 2015, 216, fn 109). Just so, contemporary Brazilian pirarucu fishermen consider that these majestic fish deserve to be caught in an inter-subjective duel, and they depreciate fishermen who resort to 'cowardly' nets that negate the exercise of the fish's will, and break the trust established by the throwing of a harpoon (Sautchuk n/d). Happily, their ethics has recently found an echo with conservation initiatives. The issue of mediation, not only how much, but what kind, is thus central to the definition of entrapment and to its valueladen tension with hunting 'proper'.

Otis Mason, anthropological pioneer in the study of traps, proposed that a trap required 'the complete detachment of man' (Mason 1900, 5), so that any technique requiring man's 'constant cooperation' did not qualify. In his striking definition, a trap 'is an invention for the purpose of inducing animals to commit incarceration, self arrest, or suicide' (Mason 1900, 4). Following in Mason's footsteps, Julian Lips, who conducted salvage ethnography with Northeastern Algonkian people, imagines 'primitive man' passing days lying in wait for an animal with his spear or bow at the ready, and the dawning realisation that he might substitute his own hand for a mechanism of release and attack (Lips 1936, 6). In other words, the substitution of man by mechanism has been central to the anthropological imaginary of trapping, which has been closely tied to evolutionary narratives about technology and cognition, a point that we will expand upon below.

Mason's ideas are good to think with, if what we want to think about is technology, automation, cognition and the dispersal of human agency through things. But the polarisation of hunting and trapping belies the continuum of predatory strategies we find in the world. For one thing, most fishing practices muddle and muddy this border, involving bait, nets, hooks, baskets and poisons, all of which require the presence of the fisherperson but entail passive anticipation, rather than active encounter. With the exception of the diver who goes to spear fish in their dominion, catching fish usually involves mediating tools and technologies. Of these, completely autonomous traps are the exception rather than the rule.

In the terrestrial domain, too, many hunting methods entail modifying the landscape such that it is moulded into a trap. For example, in the Finke River region of Australia, hunters prepare the landscape by erecting two semi-circular fences around a water hole. Emus eventually come to drink, passing through the two gaps. When there are many emus inside, the watchful hunters stretch nets over the openings, jump over the fence yelling, and drive the panicked emus into the nets (Anell 1960, 4). Such drives into corrals or deadfalls, common worldwide, adapt features of the landscape for deadly effect. 
Meanwhile, the efficacy of other hunting methods such as lure, ambush, mimicry and disguise rest on turning the body of the hunter itself into a trap - these are the kinds of methods discussed by Hermione Spriggs in her article in this Issue. To give one example, Amahuaca hunters in Amazonia hide behind blinds, disguise their bodies with paint, mask their scent with fragrant leaves, and stay downwind of prey. Like most hunters, they seek not only invisibility but powers of attraction, mimicking the animal's cry to draw it closer in order to be able to shoot from close range (Carneiro 1970, 33536).

Nonetheless, immediacy and distance remains an important emic contrast in many hunting societies, even where it does not straightforwardly map onto the trap/encounter binary. For example, the Huaorani, also of Amazonia, draw a distinction between 'blowing' monkeys and spearing peccaries. They stress the composure and care with which silent hunters 'blow' their arboreal prey by projecting a lightweight, poisontipped arrow through a long tube with a puff of breath. Peccaries, meanwhile, are killed in a collective hunt by warriors donning spears in a close range, bloody battle that leaves large wounds (Rival 1996). In the realm of fishing, the Amazonian Enawenênawê reserve dam fishing, which involves men in an ethic of restrained anticipation and reflection - a holistic subjection that is the focus of Chloe Nahum-Claudel's paper in this Issue - for their rites of civilisation, while in their season of warfare they shoot fish in a martial posture, erecting fences across oxbow lakes, using plant toxins to drive the gasping fish towards an outlet, and then standing atop their boats to shoot them with arrows from on high. Here the emic contrast is between the collective war waged on a voraciously predatory species of fish, and the ideologically consensual harvest of sociable, vegetarian, shoal-living fish (Nahum-Claudel, 2018).

In this Issue we are not wedded to a restrictive definition of trapping, or to polarised purifications of what constitutes hunting versus trapping, except where they aid our conceptualisations. Thus, Heather Swanson's article in this Issue hinges on moralised evaluations of contrasting degrees and forms of mediation. The divide is between impersonal, alienated mechanisation - permanent salmon weirs that harvest fish with brutal efficacy - and gillnets cast by the hands of poor fishermen. In an earlier era, nets were celebrated for their low-tech, humble quality that was indexical of a certain American pioneer spirit, but they are now condemned by conservationists for their lowtech immediacy - for killing salmon regardless of their contribution to species diversity. Nick Seaver's exploration of the infrastructures that undergird our experience of the Internet, is served by the restrictive definitions offered by Mason (1900), and closely followed by Gell (1996), since in this case the relationship between users and the people behind the enchanted algorithms that aim to hook them in, is densely mediated by an infrastructure made up of data, algorithms, technologies and knowledge practices. On the other hand, Spriggs's works with a loose definition of the trap as a portal between Umwelts, and her objects of reflection are hunters' aids like decoys and disguises, which are things that mediate between hunter and prey, representation and reality, but do demand the hunter's presence.

\section{The Empires of Trapping}

Noting that the Hudson's Bay Company exported around 100,000 beaver skins annually over the course of nearly two centuries, in The American Beaver and His Works Morgan stated that the animal had 'contributed, with his life, in no inconsiderable degree, to the colonization and permanent settlement of the Canadas and the United States' (Morgan 
$1868,245)$. While his comment was meant to stress the extent to which the nation had been built on the wealth of fur exports, the implication of his wider presentation of beavers' 'patient and long-continued labor' (Morgan 1868, 82) is that beavers had previously domesticated the American landscape, in a manner that was analogous to the laying of railroads by men such as himself.

Morgan's study stands out against an abiding scholarly disinterest in commercial trapping in historical and anthropological studies. As Robert Wishart points out in his article in this special Issue, the tendency in studies of the fur trade has been to assume that once steel-traps supplied by foreigners supplanted locally crafted wooden technologies, trapping became simply a barbarous pursuit of profit, alienated from the lives of indigenous hunters. This tacit idea justifies the neglect of actual trapping practices in work on the fur trade, which focus narrowly on commodity exchanges of furs, samples, commodities, or bodies, and pay little attention to the lives and arts of the trappers themselves (e.g. Ray 1998).

In stark contrast, Morgan admired the 'acuteness and ingenuity' of trappers (Morgan $1868,241)$ and never assumed that it was lessened by their reliance on imported steel traps. Men like Captain Bridges, a track master on Morgan's new railway line who moonlighted as a trapper, gave Morgan both the skulls that contributed to the exhaustive collection of specimens that supported his anatomy studies, and also his knowledge of beaver behaviour. Moreover, in the 'animal lore' of Indian trappers (Morgan 1868, 267) Morgan found clues that guided his observations. Morgan stressed that he sought out their savvy about trap placement and design in particular because one could learn a lot about a creature from how a seasoned trapper had determined that they could best be captured. We could obtain his anatomical specimens with ease because trappers hung the skulls of beavers whose fur they had taken from the trees along their trap lines. Morgan reflected that the sight of these skulls both boosted trappers' spirits when they were discouraged by an unproductive trapline, and worked on beavers' minds as well, resigning them to their inevitable fate and so hastening their entrapment (Morgan 1868, 242).

Morgan's candid account of Captain Bridges' helping hand in the collection of specimens, and his interest in the practices of trappers in general, stands out for its singularity in histories of scientific expeditions. In sixteenth and seventeenth century natural history voyages the provenance of specimens is rarely if ever reported. Specimens are simply described as being 'taken' and the practical matter of trap-use is bracketed off (Margócsy 2014). Trapping is thus reduced to a question of supply. This is probably because samples were typically purchased or otherwise obtained after they had already been trapped, prepared and traded (Parsons and Murphy 2012) so that the environmental and technical knowledge required to capture animals was kept deliberately outside the circuitry of commercial and scientific projects that sanctioned metropolitan interests. Thus trapping was a mark of alterity within regimes of natural history and mining. Morgan was, and remains, unusual in taking trapping seriously as a consequential infrastructure for economies and nation making, for trappers, for beavers, as well as for the animal behaviour studies he was pursuing.

Both Swanson and Wishart tackle the question of the political economy of trapping in their articles in this Special Issue. By paying close attention to how trapping is integrated in shifting ecologies of attention and resource-extraction, where the skills and 
social status of trappers often undergo dramatic but also generative changes, their accounts contribute towards a richer understanding of how material and social relations - how processes of entrapment, as we would like to think of them here - respond to but also stand in defiance of power asymmetries.

\section{The Archaeology of Traps: On Cunningness and the Rise of Modern Cognition}

There is a wonderful passage in The American Beaver and His Works where Morgan described an Indian trapping method involving drowning beavers by discovering and then palisading their underwater winter food stores (Morgan 1868, 236-237). As Morgan explains, upon discerning the beaver's underwater approach by subtle signals, the watchful Indian removed one wooden pole from the palisade. Searching for an entry point, the beaver entered its store. By replacing the pole, the trapper prevented the beaver's escape, and the beaver drowned. Beaver sociality dictated that the rest of the family would be sure to follow, one by one, in order to discover the cause of the first's absence. In this way a whole family could be captured at once. Morgan reserved the term 'cruelty' for the cunning intelligence of this trap, rather than for the brutal, maiming steel snares that often allowed beavers to break free, leaving their forelimbs behind. Curiously, cruelty, for Morgan, was outwitting the beaver, exploiting its impressive 'forethought and intelligence' in stocking up on winter stores (Morgan 1868, 169), as well as its sociability, to cause its most beaverish demise (Morgan 1868, 236237). He preferred that beavers should accidentally step into even quite poorly concealed snares.

While Morgan takes the side of the beaver, so that it is scandalous to him that beaver intelligence should be upstaged, a dominant trend in the history of anthropological work on traps is to celebrate, rather than condemn, just such technical and crafty accomplishment by humans. Traps' intricate mechanics have thus been taken to offer insights into the operations and development of complex cognition, both in an older anthropological tradition and in contemporary archaeology. Take for example Otis Mason's aforementioned classic 'Traps of the Amerinds' (1900). For Mason the study of traps offered insight into the 'study of Amerindian intellect and of the primitive mind in its earliest struggles with problems in mechanics and engineering' (Mason 1900, 675). Traps are designs that embody principles of automation and efficiency, no matter how incipiently or tentatively: 'the thought of the hunter [gets] to be locked up in [the trap's] parts ready to spring into efficiency at a touch.' (Mason 1900, 660)

For Mason and Julius Lips (1936) the invention of the trap fits into an evolutionary narrative of the triumph of human intellect and the diffusion of its ingenious designs. Lips imagines the dawning realisation in the mind of the hunter that he might substitute his own hand for a mechanism of release and attack until, 'by a clever construction ... [the hunter] forced the animal itself to actuate the release ... and thus had the animal act as his own eye, so to speak' (Lips 1936,6). He thus classified traps according to the kind of force the animal was tricked into releasing. In the case of pit traps, snares, nets and conical fish traps, the trapper replaced his own physical effort with the weight or motive force of the animal; in the case of dead-fall traps, that force is provided by gravity, which ensures that a trunk or rock, once dislodged, will fall on the prey; and in the case of spring, torsion or bow traps, it is the elasticity of a branch or string (Lips 1936, 6). 
As discussed above, for Mason and Lips, practices that combine traps with a human presence, such as driving animals into disguised pits, towards snares, or into corrals, are excluded. The trap is in its essence an automated substitute for a person and a mediator of a predator-prey relationship. This idea of the trap as a repository of agency is also, as we will see, at the heart of Gell's appreciation of traps' status as art works. Indeed Lips' idea of the animal's perverse destiny in acting 'as his own eye' to unwittingly take the place of its predator, brings to mind Gell's description of traps as 'a lethal parodies of the animal's Umwelt' (Gell 1996, 27).

The view that traps operate as 'mechanical servants', such that it is not only 'physical work but also intellectual work' (Brandstetter 2012, 346) that their designs embody, would go on to assume a canonical status in much twentieth century anthropological theory. In fact, as Brandsetter has demonstrated, the idea of traps as the 'first robots' (after Lips 1947) resonated beyond evolutionary anthropology. It was a view shared by historians of technology who were Lips's contemporaries. In the work of Hugo Theodor Horwitz (1924) for example, traps figure as the first relay mechanisms and thus as primitive information processors. According to Brandstetter, Horwitz depicted traps as energy transmitters capable of alternately storing and relaying energy in the moments prior and subsequent to capture. The simple mouse trap, which is a small baited snare, is conceived as a proto-computer: 'in the common mousetrap, the spring-loaded bar represents the energy reservoir, and the trip the trigger. The energy exerted onto the trigger is completely independent from the energy released by the spring. Thus, there are two sources of energy and one relay that establishes communication between them' (Brandstetter 2012, 346). It is this relaying principle that establishes traps as 'the first information-proceeding [sic] devices, the precursors to the open machines of the age of cybernetics' (Brandstetter 2012, 351).

The image of traps as automata or robots, indeed, their modelling on the principles of cybernetics, has prevailed to this day. It partakes of a longer history of fascination with 'devices of wonder', interest in the clockwork mysteries of 'perpetual motion' and in illusions of self-movement (Stafford and Terpak 2001; Schaffer 1999). It underpins also Gell's celebrated anthropological theory of traps as technologies of enchantment (Gell 1996). Gell famously described the trap (in this particular case, an arrow trap) as

an automaton or robot, whose design epitomizes the design of its maker... It is equipped with a rudimentary sensory transducer (the cord, sensitive to the animal's touch). This afferent nervous system brings information to the automaton's central processor (the trigger mechanism, a switch, the basis of all information-processing devices) which activates the efferent system, releasing the energy stored in the bow, which propels the arrows, which produce action-at-adistance (the victim's death). (Gell 1996, 27)

The problem with the cybernetic model of traps and with this anthropological legacy that approaches traps as models of cognitive or intellectual motion, is that they aim to explain how traps work rather than describe the kind of work they do. Traps stand as 'models for' technical efficiency, energy or information, and they are confined in the role of telling a grander story about technological invention and advancement. We remain in the dark, however, as to what they may be relators of, that is, what relations they inhabit as well as what forms of description they enable. Thus, Mason ignored the rituals of purification, taboos or magical spells with which American Indians engage in the work of trapping. And although Gell is explicitly concerned with the mediating role 
that traps play between species and ecologies, he still narrows this role to the technology's capacity for social enchantment.

Theories of traps have therefore largely construed cleverness and technique from a specific Western epistemological tradition, where the designs of the mind operate to 'deceive' or 'trick' nature, that is, where designs are conceived as a means to cajole nature out-of-synch with itself - traps, then, as devices designed to provoke ontological perturbations. Gell insinuates as much when describing a 'type of fishing trap among the Barasana... known as the trap "which turns fish into fruit". Given this information, one sees at once how wittily metaphysical and magical this trap is' (Gell 1996, 32). The philosopher of media Vilém Flusser has captured succinctly the thrust of this distinguished line of reasoning:

The word [design] occurs in contexts associated with cunning and deceit. A designer is a cunning plotter laying his traps. Falling into the same category are other very significant words: in particular, mechanics and machine. The Greek mechos means a device designed to deceive - i.e. a trap - and the Trojan Horse is one example of this. Ulysses is called polymechanikos, which schoolchildren translate as 'the crafty one' (Flusser 1999, 17)

Shifting to a different register now, the centrality awarded to traps as repositories of complex thought has recently been picked up by archaeologists in the study of human evolution and the chimerical question of the emergence of modern cognition. For a long time the archaeological record has remained a recalcitrant repository of evidence for this purpose (skulls give us only brain size, a poor proxy for cognition, and only stone tools are conserved). What types of artefacts embodying 'modern cognition' could count as archaeological survivals from our deep past?

One suggestion has been to look out for examples of material culture that unequivocally demand from their creators a specific repertoire of distributed cognitive relations, for example, 'enhanced working memory' (EWM) and 'executive functions' (EF) evidenced by long-range planning, scheduling or a complex coordination of time and space (Coolidge and Wynn 2005). As it turns out, traps are among the very few types of archaeological objects that cognitive scientists believe provide sufficient evidence for the presence of EF and EWM. As Thomas Wynn and Frederick Coolidge have put it,

traps and snares, are often multicomponent gadgets, occasionally very heavy, that are time-consuming to build, and which operate remotely, occasionally in the absence of direct human engagement. It is the remote action that implicates EFs and EWM. To make a trap one must project present action toward a future, uncertain result. This requires the long range planning in space and time of modern EFs, and relies significantly on the response inhibition of the central executive of WM (delayed gratification). (Wynn and Coolidge 2011, 5)

Such a hypothesis has enabled archaeologist Lyn Wadley to argue for the use of traps and snares at Sibudu, a South African Middle Stone Age site, and to recommend research into these technologies as proxies for the presence of complex cognition 70,000 years ago. Trap use is inferred in this and other studies based on the presence in faunal assemblages of large numbers of animal bones from species most easily caught in traps. As Wadley puts it, people 'who made snares in the deep past were early 
natural-scientists who observed animal behavior, planned the setting of snares accordingly, and then relied on their judgment to realize the remote capture that they could visualize from a distance.' (Wadley 2010, 188)

The cognitive abilities ascribed to hunters in this view revolve around their capacity to model an animal's habitat, and the skills by which they prefigured a moment of capture distant in space and time. Another way of saying this is that the setting of traps had to interrupt the flow of hunting, dislocating the spaces and times of abduction and capture. Therefore, hunters' cognitive relations with an environment - their memory of it, their ability to read and interpret landscape, their understanding of seasonal and animal rhythms - are modulated by the arts of trapping, which somehow come to disturb and reorganise the spatial and temporal dimensions of faunal assemblages. Traps would seem to embody a complex 'ecology of mind' (Bateson 1999).

A different strand of cognitive archaeology has also recently turned to Bateson's notion of an ecology of mind to argue for a distributed approach to cognition. We refer here to so-called Material Engagement Theory (MET) (Malafouris, 2013). While traps do not figure centrally in the writings of Malafouris and other cognitive archaeologists sharing an MET agenda, we believe there is ample scope for using entrapment to bring these traditions of cognitive archaeology into conversation with anthropology. Let us outline briefly some of the key issues at stake here.

The driving insight for MET is that 'human intelligence 'spreads out' across the bodyworld boundary, thus extending beyond skin and skull into culture and the material world' (Renfrew, Frith, and Malafouris 2008, 1936). Malafouris has coined the term 'tectonoetic' consciousness (from the Greek tecton, carpenter or builder, and more generally, the poetic art of construction) to note how the process of noesis or thinking is always and everywhere constructed through our material engagement with the world (Malafouris 2008, see also 2015). Chris Gosden conceptualizes the co-evolving plasticity between brain, body and world more amply as a 'social ontology' where 'brains help make new objects, which in turn help create new brains' (Gosden 2008, 2005). Christopher Tilley (2004), and Ian Hodder (2011) have similarly placed the lives of material forms at the centre of anthropological inquiry for quite some time now, drawing attention to the textural and granular vicissitudes of things that hold worlds together.

We wish in this light to foreground the purchase of traps as a site for an interdisciplinary conversation between archaeology, cognitive science and anthropology - for grounding material, ecological, evolutionary and cognitive approaches to the study of human life. Traps are more than proxies for practical or conceptual reason. They are material entanglements of lives, designs for complex and fraught relationships across the boundaries of the human and the nonhuman.

\section{The Anthropology of Entrapment}

The preceding sections have offered us a glimpse of the various ways in which traps have traditionally been described in anthropology, archaeology and cognate fields as vectors of material, ecological and social agency. Traps have helped centre discussions about material culture and social infrastructures, about resource extraction and environmental equilibriums, about skilled cognition and empirical intelligence. In this last section we wish to essay a different route to signal the importance of traps for 
anthropological scholarship. We want to take stock of the foregoing discussion to propose the notion of 'entrapment' as an anthropological heuristic for social process.

We wish to suggest that our usual interest in traps as technological artefacts - as devices of mechanical wonder and cunningness - has meant that we have failed to pay quite as much attention to how the movement of 'entrapment' is distributed across times and spaces, objects and agencies, intensities and extensions. The trap is not just a technology or artefact standing 'separate' from social or ritual practices. Rather, it is a complex architecture of gradations where bodies and landscapes and nonhuman persons move and orient their capacities towards one another in an uncertain game of alignments. The architecture of these inclinations and complicities, these unstable dispositions, surfaces as a process of entrapment. The trap is therefore no longer something outside relations, a void a prey falls into, but a modality of relationality, an ecological sensibility of encounter, where particular ontological and bodily experiences are given a sublime expression. Bodies that move towards traps and entrapments that move through embodiments.

We are aware that the figure of entrapment lends itself to playful and metaphorical appropriations - just think of all the trap idioms you use. The notion of entrapment we are putting forward here, however, builds its analytical powers on specific ethnographic insights. In particular, the description of entrapment as a social process that is continually animated by material, ecological and relational energies takes inspiration from three types of ethnographic accounts of trapping: (i) narratives of traps as sentient or animate beings; (ii) narratives about the shaping or modulation of traps into environments or landscapes, and (iii) narratives about the ritual transformation of human and nonhuman persons through their involvement in trapping.

These three narratives about the animism, ecology and relationalities of traps invite a reconsideration of trapping, not simply as a technology of encounter, but as a modality and sensibility of engagement more amply - as entrapment. We shall now look at each of these dimensions in turn, whilst noting that our separating them here is done simply for explanatory purposes. In each example, all three facets of entrapment are in play.

\section{Animism}

Robert Losey has recently made a persuasive argument for approaching the study of fish dams and weirs in the Northwest Coast of North America as 'sentient beings' in their own right (Losey 2010). It is well known that native people regularly addressed salmon 'as kin or friends, [who] had social structures like those of human persons (belonging to clans, having chiefs, etc.), and sometimes lived in wooden houses in the ocean' (Losey 2010, 19). As part of the animate world engaged in by both fishes and humans, fishing equipment was also potentially sentient. Because fishing was conceived as a social interaction between sentient human and nonhuman entities, the construction, use and abandonment of fishing technologies was carried out in prescribed ways (Losey 2010, 20).

Thus, halibut hooks were addressed, as were fishing nets. Losey cites Boas' report on the Kwakwaka'wakw of central British Columbia (Boas 1966) who referred to their hooks as "Younger Brothers", and termed the bait attached to their barbs "blankets" or "dress" (Losey 2010, 20). Among the Salish speakers of the Gulf Islands of northern Washington State, fishing nets called for similar ritual treatment, for they 'consider their 
net to represent a human being head, body, arms and legs, and they believed that unless it was set in a definite way the leading sockeye would turn back disapprovingly and warn those behind' (Suttles 1974, 163, cited in Losey 2010, 20). This would explain, Losey notes, why fishing structures are so poorly preserved in the archaeological record, since their status as sentient beings would require native populations to have them dismantled, or partially disassembled them, to prevent the unnecessary killing of future animals. Indeed, we have rich ethnographic record of contemporary fishing dams and labyrinth fish fences in Amazonia, where these too are partially or completely dismantled to allow for fish regeneration, and are surrounded with observances that regulate a risky, always potentially reversible predatory relationship between people and fish (Nahum-Claudel 2017 and this Issue).

Accounts of scrupulous management of interspecies relationships are indeed common in the literature on hunting and trapping. Among the Siberian Yukaghirs, the days prior to the hunt would be spent staging a game of 'sexual seduction' and 'lustful play' with the animal spirits in the hope that the latter will believe 'that what is going on is not a premeditated kill but a "love affair" with the hunter' (Willerslev 2007, 48). Trappers would similarly leave decoys behind to distract irate spirits away from their trail of blood (Willerslev 2007, 129). In the case of the Kepel fish dams reported by Thomas Waterman and Alfred Kroeber, the 'master mechanic and general superintendent of the fish-dam enterprise' (Waterman and Kroeber 1938, 51), was also a 'medicine man'. In the days preceding construction work he would set out in search of young firs to be used as stakes. Each tree of his liking was addressed with the remarks, "I want good luck", "I want everybody to be happy. I do not want any sickness", (Waterman and Kroeber $1938,55)$. Once trimmed into a stake he would then refer to the tree as " "that-one-whohas-ears," referring to the fact... that it "listens" to the shaman's request.' (Waterman and Kroeber 1938, 55)

In light of these distributions of agency between predator, prey and trap, we propose that traps are not artefacts mediating relations, but rather sources of relational agency in their own right. They are forms that help us see the vital and dynamic materialities accompanying multispecies social processes. As Nahum-Claudel's contribution illustrates, a trap is a nexus of intentionalities, one that is not only constructed and maintained in order to capture prey, but also in order to transform people's social lives, subjective experiences, and cosmological orientations.

\section{Ecologies}

In other words, traps are always technologies of inhabitation as much as they are technologies of predation. They are material designs for projects of co-habitation. Traps terraform a relationship between people, prey, and the physical and invisible landscapes that they share. For instance, ethnoarchaeologist Alejandro Haber (2009) describes the northern Argentinean desert as what we term a landscape-trap. Haber has found evidence that hunters placed tools and obstacles across the land to reorient the passage and circulation of vicuña (a close relative of the llama) in the expectation that a future hunter might someday benefit from an encounter with the prey and then have tools handy to butcher it. He calls these 'landscapes of anticipation' (Haber 2009, 427) because the terrain was continually modified in preparation for envisaged hunts, taking place perhaps a few days later, but also, as Haber notes, perhaps a couple of millennia later (Haber 2009, 425). Hunters were modelling their and the animals' habitats after a 
logic of entrapment, where the trap was no longer a technology but an ecology: a design for mutual co-habitation.

This is not an exceptional case. Trapping infrastructures often shade into landscape, ecology and history in this way. For example, before Kalahari hunters set their snares, they gradually connect up bushes in their desert landscape by adding brush to create zig-zag lines. They do this little by little over the days so that their prey will not notice, but rather get accustomed to their new landscape and forge habitual paths within it. Once the duiker or steenbok have trodden their habitual paths across these subtle barriers, spring rope snares are set in precisely those crossings (Lee 1979, 207-8; Silberbauer 1981, 272). At the height of the summer season when every man sets three such brush-and-snare lines in the surrounds of a camp the whole terrain becomes a trapecosystem that brings in a steady return of meat.

Fish weirs also have this seasonal, terra-forming aspect, and as Swanson's contribution shows, put to work for profit, they also had the capacity to turn the Columbia River into a permanent fish factory capable of over-supplying the canneries. In the Baure region of the Bolivian Amazon, pre-Columbian networks of hydraulic earthworks have been excavated and described as permanent complexes of 'intensive aquaculture' (Erickson 2000, 191). Here wooden fish weirs were probably built on top of a permanent earthwork infrastructure, as a means to manage and harvest the fish that migrated to spawn in the inundated savannahs during the wet season. Thus according to Clark Erikson, the people of Baure 'domesticated the landscape', 'rather than domesticate the species that they exploited' (Erickson 2000, 192).

All of the above examples of landscape-traps bring up the question of domestication and challenge the certainty with which we define traps as 'hunting technologies'. In archaeology and anthropology, hunting and domestication have traditionally been strictly delimited, attached to separate temporalities, economic systems or cultures. However, recent work on the material architectures of human-animal encounter is changing some of our preconceptions in this regard. Among Mayan communities, a specific technique of slash-and-burn agriculture, known as the 'milpa trough-trap', is used as a 'habitat management practice' the aim of which is to hunt animals rather than cultivate products (Santos-Fita et al. 2013). In a recent article on architectures of domestication - including tethers, enclosures and traps - among various circumpolar Arctic societies, David Anderson and his colleagues have shown how these infrastructures are better conceived as ecologies of conviviality (Anderson et al. 2017). Thus, they reserve the term 'domestication' in this context to evoke an environment properly aligned to live a good life of mutuality - 'a space where more than one animal creates convivial places which are good to live in' (Anderson et al. 2017, 400). This again, is a terrain in which entrapment invites further collaboration between anthropologists and archaeologists.

\section{Relationships}

There is a well-known passage in The Savage Mind where Lévi-Strauss describes the Hidatsa tradition of eagle trapping (Lévi-Strauss 1996, 50). The Hidatsa hide in deep pits covered by a frame made of branches of buckbrush bounded together by blue grass (Wilson 1928, 121). Using a jackrabbit or deer breast as bait, hunters thrust themselves out from the pit to seize the eagle's legs with their bare hands as the animal perches on the bait. As Lévi-Strauss famously put it, 'the technique presents a kind of a paradox. 
Man is the trap but to play this part he has to go down into the pit, that is, to adopt the position of a trapped animal. He is both hunter and hunted at the same time' (LéviStrauss 1996, 50 emphasis in the original). Lévi-Strauss used the example of the Hidatsa man-trap to outline a series of structural oppositions and mediations, between the flying eagle and the subterranean hunter, or between the shedding of blood in the killing of the bait and the bloodless capture of the eagle.

Whilst Lévi-Strauss's analysis of Hidatsa eagle trapping deftly avoids the question of technology, entranced instead by the structural mythology of hunting, he shows surprisingly little interest in the ceremonies surrounding eagle trapping. We cannot offer a comprehensive review of this literature here. However, there are some aspects we would like to engage with summarily to show how there is more to the architecture of trapping than its technical or mythological complexes. Let us go back to the Hidatsa for a moment.

Ethnographies of eagle trapping tell us how hunting parties often stayed in the woods for weeks at a time. Upon arriving at a camping site they would construct a hunting lodge. Once built, the leader of the party would offer prayers to the sacred objects he had brought along (a black bear feet, soft feathers from under an eagle's wing or tail, a buffalo skull), asking permission to enter the lodge (Wilson 1928, 145). Hunters would then each be given a name and assigned a specific bed. Women were not allowed into the eagle hunters' lodge and stayed in a camp of their own, except in the case of menstruating women, who were ceremonially invited in to make 'sure that many eagles would be caught.' (Wilson 1928, 169) Thus, there was a constant attention to specific alignments of objects, movements and people: their proper seating arrangements during a ceremony, their facing eastwards or northwards, the direction of walking, the comportment of bodies, etc. James Howard similarly noted of the Yanktonai Dakota that upon returning from an eagle trapping foray each 'man was careful to carry his eagle so that they head of the bird pointed toward the camp' (Howard 1954, 72). It appears, also, that hunters had to wait four days before the feathers of the eagles could be removed (Howard 1954, 73).

The material intimacy and attentiveness that the ritual handling of traps and prey calls forth, as well as the indeterminacy and instabilities - the perils and risks, the visions and intuitions, the unstable reversals between hunter and prey - that they inscribe, invites a reconsideration of the role of traps as descriptors of anthropological complexity. There is a sense in which as an extended ecology of practices traps are designed to mobilize, assemble and orient the circulation of energy in specific directions. Thus, in preparation, energies are gently and respectfully, sometimes seductively, swayed towards the trap, whilst in the days following the collection of the prey they are carefully redirected and funnelled away from the agonic intimacy of predation. Bodies move in and out of traps, but it is not always clear whose body will be trapped and what exactly traps embody. Traps function thus as passageways for the circulation of 'endo- and exo-energies' (Corsín Jiménez, forthcoming), energies that coalesce around bodies and bodies that dissipate into energies. They work as at once conductors and insulators of connectivity, accelerators and decelerators of mutuality or estrangement; as entrapments that body forth promissory but also dangerous worlds.

The point is eloquently made by Nahum-Claudel in her article for this Special Issue. Among the Amazonian Enawenê-nawê, the activity of fish-dam building undergoes 
cyclical stages: first, the strenuous bodily effort required to build a weir in the middle of a deep rushing river is likened to the original world-making gestures of the creator deity. The men move between land and water, 'moulding and domesticating the riverine landscape', as she puts it. Next, once the weir is in place, the men take to the crafting and placing of traps, an activity which is likened instead to the communal embrace of 'mental and social techniques [that will] generate the convivial and fertile atmosphere that is 'desired' by their animate traps'. This requires them to take a certain distance (geographic and ritual) from the traps, for risk of ultimate self-entrapment. Therefore, the material and ritual risks that traps pose as predatory designs, for others as well as for ourselves, speaks, inevitably, of their agency as architectures of entrapment.

It is our hope that this Special Issue will contribute towards reawakening anthropological interest in traps. Traps are not only 'good to think with'; they are also carriers of thought in themselves. They are material vehicles, as archaeologists have begun to point out, for complex and distributed cognition. And not just thought: traps embody the architectures of care and understanding through which human and nonhuman persons share residence in an environment. They are designs for cohabitation. The anthropology of traps is therefore a privileged site for exploring the recursive entanglements of materiality, ecology and social life. Indeed, going beyond what we have begun in this text, there may be an argument for thinking of entrapment as a heuristic for social processes in general.

\section{References}

Anderson, David G., Jan Peter Laurens Loovers, Sara Asu Schroer, and Robert P. Wishart. 2017. "Architectures of Domestication: On Emplacing Human-Animal Relations in the North." Journal of the Royal Anthropological Institute 23 (2): 398-416. doi:10.1111/1467-9655.12613_1.

Anell, Bengt. 1960. Hunting and trapping methods in Australia and Oceania, Studia Ethnographica Upsaliensia XVIII: Uppsala.

Bateson, Gregory. 1999. Steps to an Ecology of Mind: Collected Essays in Anthropology, Psychiatry, Evolution, and Epistemology. Chicago, IL: University of Chicago Press.

Boas, Franz. 1966. Kwakiutl Ethnography. Chicago, IL: University of Chicago Press.

Brandstetter, Thomas. 2012. "The Lives of Mechanical Servants." Interdisciplinary Science Reviews 37 (4): 345-53. doi:10.1179/0308018812Z.00000000027.

Carneiro, Robert L. 1970. "Hunting and Hunting Magic among the Amahuaca of the Peruvian Montaña." Ethnology 9 (4): 331-41. doi:10.2307/3773039.

Cartmill, Matt. 1996. A View to a Death in the Morning [electronic resource]: Hunting and Nature through History, Cambridge, Mass.: Harvard University Press.

Coolidge, Frederick L., and Thomas Wynn. 2005. "Working Memory, Its Executive Functions, and the Emergence of Modern Thinking." Cambridge Archaeological Journal 15 (1): 5-26. doi:10.1017/S0959774305000016.

Corsín Jiménez, Alberto. forthcoming. "The Deep Trap.” In Spiderweb Anthropologies: The Arts and Traps of Complicity and Complexity.

Detienne, Marcel and Vernant, Jean-Pierre. 1991 [1977]. Cunning Intelligence in Greek Culture and Society, translated by Janet Lloyd, Chicago: University of Chicago Press.

De Waal, Franz, 2017. Are We Smart Enough To Know How Smart Animals Are? New York: W.W. Norton \& Company Inc. 
Erickson, Clark L. 2000. "An Artificial Landscape-Scale Fishery in the Bolivian Amazon." Nature 408 (6809): 190-93. doi:10.1038/35041555.

Flusser, Vilém. 1999. The Shape of Things: A Philosophy of Design. London: Reaktion Books.

Gell, Alfred. 1996. "Vogel's Net: Traps as Artworks and Artworks as Traps.” Journal of Material Culture 1 (1): 15-38. doi:10.1177/135918359600100102.

Gosden, Chris. 2008. "Social Ontologies." Philosophical Transactions of the Royal Society of London B: Biological Sciences 363 (1499): 2003-10. doi:10.1098/rstb.2008.0013.

Haraway, Donna J. 2008. When Species Meet, Minneapolis: University of Minnesota Press.

Haber, Alejandro F. 2009. "Animism, Relatedness, Life: Post-Western Perspectives." Cambridge Archaeological Journal 19 (3): 418-430. doi:10.1017/S0959774309000602.

Hodder, Ian. 2011. "Human-Thing Entanglement: Towards an Integrated Archaeological Perspective." Journal of the Royal Anthropological Institute 17: 154-177.

Holliday, Trenton W. 1998. "The Ecological Context of Trapping among Recent Hunter-Gatherers: Implications for Subsistence in Terminal Pleistocene Europe." Current Anthropology 39 (5): 711-19. doi:10.1086/204794.

Horwitz, Hugo Theodor. 1924. "Über Die Konstruktion von Fallen Und Selbstschüssen." Beiträge Zur Geschichte Der Technik Und Industrie 14: 85-100.

Howard, James H. 1954. "Yanktonai Dakota Eagle Trapping." Southwestern Journal of Anthropology 10 (1): 69-74.

Lee, Richard. 1979. The !Kung San: Men, Women, and Work in a Foraging Society, Cambridge: Cambridge University Press.

Lévi-Strauss, Claude. 1996. The Savage Mind. Oxford: Oxford.

Lips, Julius. 1936. Trap systems among the Montagnais-Naskapi Indians of Labrador peninsula / by Julius E. Lips, Stockholm: Stockholm : Statens etnografiska museum, 1936.

- - - 1947. The Origin of Things. New York: A. A. Wyn.

Losey, Robert. 2010. "Animism as a Means of Exploring Archaeological Fishing Structures on Willapa Bay, Washington, USA.” Cambridge Archaeological Journal 20 (1): 17-32. doi:10.1017/S0959774310000028.

Malafouris, Lambros. 2008. "Between Brains, Bodies and Things: Tectonoetic Awareness and the Extended Self." Philosophical Transactions of the Royal Society of London B: Biological Sciences 363 (1499): 1993-2002. doi:10.1098/rstb.2008.0014.

_ 2013 How Things Shape the Mind: A Theory of Material Engagement. Cambridge, Mass: The MIT Press.

. 2015. "Metaplasticity and the Primacy of Material Engagement." Time and Mind 8: 351-371.

Mason, Otis T. 1900. "Traps of the Amerinds—a Study in Psychology and Invention." American Anthropologist 2 (4): 657-75. doi:10.1525/aa.1900.2.4.02a00050.

Morgan, Lewis H. 1868. The American Beaver and His Works. Philadelphia: J. B. Lippincott \& Co.

Nahum-Claudel Chloe. 2018. Vital Diplomacy: The Ritual Everyday on a Dammed River in Amazonia, New York; Oxford: Berghahn.

Peckham, Robert. 2015. Game of Empires: Hunting in Treaty-Port China. In: Beattie J, Melillo E and O'Gorman E (eds) Eco-Cultural Networks and the British Empire: 
New Views on Environmental History. New York: Bloomsbury Academic, 202232.

Ray, Arthur J. 1998. Indians in the Fur Trade: Their Role as Trappers, Hunters, and Middlemen in the Lands Southwest of Hudson Bay, 1660-1870: With a New Introduction. Toronto, Buffalo and London: University of Toronto Press.

Renfrew, Colin, Chris Frith, and Lambros Malafouris. 2008. "Introduction. The Sapient Mind: Archaeology Meets Neuroscience." Philosophical Transactions of the Royal Society of London B: Biological Sciences 363 (1499): 1935-38. doi:10.1098/rstb.2008.0016.

Rival, Laura. 1996. Blowpipes and spears: the social significance of Huaorani technological choices. In Descola P (ed) Nature and Society: Anthropological perspectives. London: Routledge, 145-165.

Santos-Fita, Dídac, Eduardo J. Naranjo Piñera, Eduardo Bello Baltazar, Erin I. J. Estrada Lugo, Ramón Mariaca Méndez, and Pedro A. Macario Mendoza. 2013. "La Milpa Comedero-Trampa Como Una Estrategia de Cacería Tradicional Maya." Estudios de Cultura Maya 42 (42): 87-118. doi:10.1016/S01852574(13)71387-X.

Sautchuk, Carlos. n/d. Pirarucu's net: On Technical Objects in the Amazon.

Schaffer, Simon. 1999. "Enlightened Automata." In The Sciences in Enlightened Europe, edited by William Clark, Jan Golinski, and Simon Schaffer, 126-65. Chicago and London: University of Chicago Press.

Schapera, Isaac. 1930. The Khoisan Peoples of South Africa, Bushmen and Hottentots, London: Routledge.

Silberbauer, George B. 1981 Hunter and habitat in the central Kalahari Desert. Cambridge: Cambridge University Press.

Stafford, Barbara Maria, and Francis Terpak. 2001. Devices of Wonder: From the World in a Box to Images on a Screen. Los Angeles: The Getty Research Institute.

Suttles, Wayne. 1974. The Economic Life of the Coast Salish of Haro and Rosario Straits. New York: Garland Pub.

Tilley, Christopher Y. 2004. The Materiality of Stone: Explorations in Landscape Phenomenology. Oxford and New York: Berg.

Wadley, Lyn. 2010. "Were Snares and Traps Used in the Middle Stone Age and Does It Matter? A Review and a Case Study from Sibudu, South Africa." Journal of Human Evolution 58 (2): 179-192. doi:10.1016/j.jhevol.2009.10.004.

Waterman, T T, and Alfred L Kroeber. 1938. "The Kepel Fish Dam." University of California Publications in American Archaeology and Ethnology 35 (6): 49-80.

Willerslev, Rane. 2007. Soul Hunters: Hunting, Animism, and Personhood among the Siberian Yukaghirs. Berkeley and Los Angeles, California: University of California Press.

Wilson, Gilbert Livingstone. 1928. "Hidatsa Eagle Trapping." Anthropological Papers of the American Museum of National History 30: 99-245.

Wynn, Thomas, and Frederick L. Coolidge. 2011. "The Implications of the Working Memory Model for the Evolution of Modern Cognition." International Journal of Evolutionary Biology 2011 (March): e741357. doi:10.4061/2011/741357. 